\title{
Effectiveness of Smartphone-Use to Alleviate Preoperative Anxiety in Children
}

\author{
Jayalaxmi Bachaspatimayum ${ }^{1}$, Langpoklakpam Chaoba Singh ${ }^{2}$, Saraswathi Ramakrishna ${ }^{3}$, Bijaya Chingtham ${ }^{4}$ \\ 1,2,3 Department of Anaesthesia, Regional Institute of Medical Sciences, Imphal, Manipur, India.
}

\section{ABSTRACT}

\section{BACKGROUND}

Preoperative paediatric anxiety is a common phenomenon usually associated with surgery and has a negative impact on postoperative recovery. Pharmacological approaches have proven useful in decreasing anxiety in children but it is not without disadvantages. Because of these concerns, non-pharmacological interventions have been explored. We wanted to evaluate as to whether usage of smartphone could alleviate preoperative anxiety in children.

\section{METHODS}

100 non-premedicated children aged 4 - 8 years undergoing surgery under general anaesthesia were enrolled in the study. Children were accustomed to the smartphone at the pre-anaesthetic visit with a choice of viewing animated videos and games. On the day of surgery the child was given the device to play for around 30 minutes at pre-anaesthetic room. The child was transported from the preoperative room by the anaesthetist while the child was playing with the smartphone and then placed on the operating table followed by attachment of routine monitors.

\section{RESULTS}

91 children underwent smooth uncomplicated gaseous induction using smartphone distraction while 9 children had to be administered with anxiolytic premedication.

\section{CONCLUSIONS}

Smartphone can be used to alleviate preoperative paediatric anxiety as a distraction technique.

\section{KEY WORDS}

Distraction, Preoperative Anxiety, Smartphone
Corresponding Author: Dr. Langpoklakpam Chaoba Singh, Sangaiprou Mamang Leikai, Near Oil Pump, Airport Road, Imphal, Manipur - 795001, India. E-mail:drchaoba@gmail.com

DOI: $10.14260 /$ jemds/2021/59

How to Cite This Article: Bachaspatimayum J, Singh LC, Ramakrishna $S$, et al. Effectiveness of smartphone-use to alleviate preoperative anxiety in children.J Evolution Med Dent Sci 2021;10(05):264-267, DOI: 10.14260/jemds/2021/59

Submission 12-10-2020,

Peer Review 04-11-2020,

Acceptance 12-12-2020,

Published 01-02-2021.

Copyright (C) 2021 Jayalaxmi Bachaspatimayum et al. This is an open access article distributed under Creative Commons Attribution License [Attribution 4.0 International (CC BY 4.0)] 


\section{BACKGROUND}

Preoperative anxiety in children is a common phenomenon that has been associated with a number of negative behaviours during the surgery expirence. ${ }^{1} \mathrm{Up}$ to $65 \%$ of children experience significant anxiety associated with preoperative period. ${ }^{2}$ The anxiety reactions are thought to be a reflection of the child's fears of separation from parents and home environment, loss of control, unfamiliar routines, surgical instruments and hospital procedures. ${ }^{3}$

Children have been observed to manifest such anxiety in many ways including appearing frightened, becoming agitated, breathing deeply, trembling, crying, not talking, sudden urination, increased motor tone or attempt to escape from the medical personnel. ${ }^{4}$

As many as $67 \%$ of children may develop postoperative negative behavioural changes including general anxiety, apathy and withdrawal, separation, anxiety, sleep disturbances, aggression towards authority and disturbance. Children who exhibit more anxiety preoperatively may be 3 times more likely to exhibit such negative behaviours. ${ }^{5}$

To reduce the incidence of preoperative anxiety in children, a number of prevention strategies have been employed. The pharmacological approaches have been proven useful but it is not without disadvantages like delay in emergence, recovery and discharge, increased incidence of maladaptive behavioural changes post-surgery, amnesia. Given these disconcerting findings, non-pharmacological strategies and psychoeducational interventions like parental presence, preoperative preparation programme, and distraction technique may be preferable.6,7

Readily available smartphones (e.g., iPhone) ${ }^{8}$ can be used as distraction aids. Most children like to play with smartphones, listening to music, watching videos or playing video games. Moreover, it has the dual advantage of distraction and shielding view of a harsh-looking operating room.

This study aims to alleviate preoperative anxiety in children undergoing surgeries under general anaesthesia using smartphone as a distraction technique.

\section{METHODS}

This was a quasi-experimental study. After obtaining approval from research ethical board, Regional Institute of Medical Sciences, Imphal and consent from the parents, a series of 100 non premedicated children aged 4 - 8 years posted for surgery under general anaesthesia were enrolled in the study. The study was conducted from June 2018 to May 2019 over a period of one year. All children of either sex aged 4 - 8 years, American Society of Anesthesiologists (ASA) category I and II undergoing surgery under general anaesthesia were included in the study. Children with uncooperative parents, with impaired mental status, on any psychotropic drugs, or with sepsis and hypotension were excluded from the study

\section{Study Variables}

1. Demographic profile: Age, sex, weight.
2. Type of surgery: All types of surgery under general anaesthesia.

Outcome variables: success distraction i.e., no sign of anxiety using smartphone distraction or failed distraction requiring administration of anxiolytic premedication.

\section{Study Tools}

Child anxiety was assessed by using the modified Yale Preoperative Anxiety Scale (mYPAS) (Appendix 1)

\section{Procedure}

During pre-anaesthetic visit, one day prior to surgery, we established good rapport with the children and their parents. Then the children were introduced to the smartphone and offered the choice of viewing animated videos and playing games. On the day of surgery, in the pre-anaesthetic room the children were given the smartphone to hold and play for around 20 - 30 minutes. 10 minutes later the mYPAS was recorded by the rating doctor who had thorough understanding of and training in assessing child's anxiety. The child was then transported without parental presence from the preoperative room to the operating theatre with continued use of the smartphone. The rating doctor again recorded the mYPAS. The child was placed on the operating table in the operating theatre and routine monitoring attached. Our study ended here. Those children who had become very aggressive with smartphone distraction were returned to the preanaesthetic room for administration of anxiolytic premedication with midazolam $0.5 \mathrm{mg} \mathrm{/} \mathrm{Kg} 9$ orally. Descriptive statistics like frequency, count and percentage was used for analysis of data.

\section{RESULTS}

\begin{tabular}{|ccc|}
\hline Children's Anxiety & mYPAS $(\leq \mathbf{3 0})$ & mYPAS $(>\mathbf{3 0})$ \\
\hline Preoperative room & 100 & 0 \\
In operative room & 91 & 9 \\
\hline \multicolumn{2}{|c|}{ Table 1. Preoperative Changes of } \\
\hline \multicolumn{2}{|c|}{ mYPAS } \\
\hline
\end{tabular}

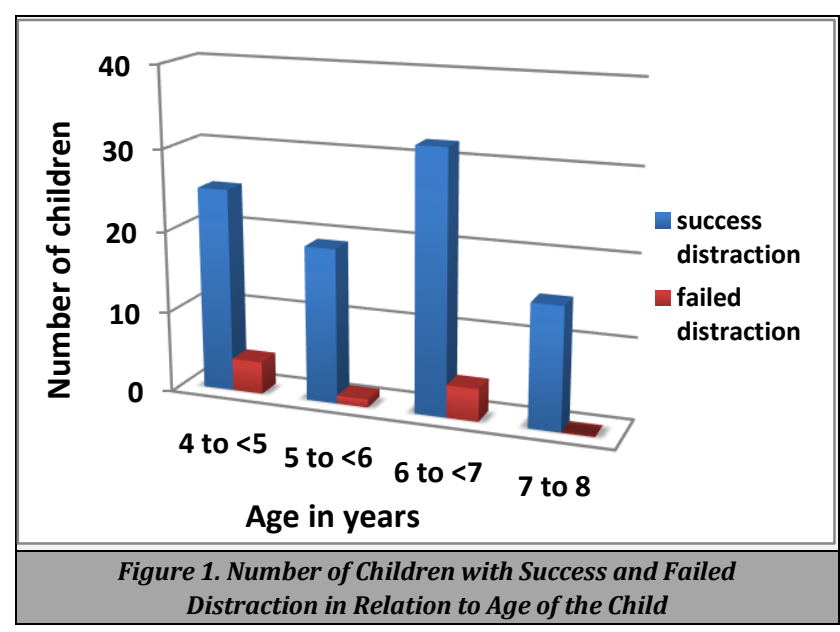

Children with mYPAS score of $\leq 30$ recorded after entry into the operating room were classified as no anxiety. The mYPAS scores remain same after entering into the operating 
room compare with the score in preoperative holding area in 91 children. Whereas the mYPAS score after entering into the operating room increased with score in preoperative room in remaining 9 children.

From the study we found that $91 \%$ of the cases could undergo smooth uncomplicated gaseous induction using smartphone distraction whereas the other $9 \%$ had to be returned to the pre-operative room for administration of anxiolytic premedication.

\begin{tabular}{|c|c|c|c|c|}
\hline Type of Surgery & $\begin{array}{l}\text { Age of } \\
\text { Child in } \\
\text { Years }\end{array}$ & $\begin{array}{c}\text { Success } \\
\text { Distraction }\end{array}$ & $\begin{array}{c}\text { Failed } \\
\text { Distraction }\end{array}$ & $\begin{array}{c}\text { Total } \\
\text { Number of } \\
\text { Children }\end{array}$ \\
\hline \multirow{4}{*}{ 1. Herniotomy } & 4 to $<5$ & 13 & 2 & 11 \\
\hline & 5 to $<6$ & 9 & 0 & 9 \\
\hline & 6 to $<7$ & 39 & 0 & 39 \\
\hline & 7 to 8 & 6 & 0 & 6 \\
\hline \multirow{4}{*}{$\begin{array}{l}\text { 2. Incision and } \\
\text { drainage }\end{array}$} & 4 to $<5$ & 6 & 2 & 4 \\
\hline & 5 to $<6$ & 3 & 0 & 3 \\
\hline & 6 to $<7$ & 3 & 1 & 2 \\
\hline & 7 to $<8$ & 4 & 0 & 4 \\
\hline \multirow{4}{*}{$\begin{array}{l}\text { 3. Inclusion cyst } \\
\text { excision }\end{array}$} & 4 to $<5$ & 0 & 0 & 0 \\
\hline & 5 to $<6$ & 0 & 0 & 0 \\
\hline & 6 to $<7$ & 0 & 1 & 1 \\
\hline & 7 to 8 & 1 & 0 & 1 \\
\hline \multirow{4}{*}{ 4. Appendectomy } & 4 to $<5$ & 0 & 0 & 0 \\
\hline & 5 to $<6$ & 3 & 0 & 3 \\
\hline & 6 to $<7$ & 1 & 0 & 1 \\
\hline & 7 to 8 & 4 & 0 & 4 \\
\hline \multirow{4}{*}{ 5. Tendon repair } & 4 to $<5$ & 0 & 0 & 0 \\
\hline & 5 to $<6$ & 1 & 0 & 1 \\
\hline & 6 to $<7$ & 3 & 0 & 3 \\
\hline & 7 to 8 & 0 & 0 & 0 \\
\hline \multirow{4}{*}{ 6. Open pyeloplasty } & 4 to $<5$ & 0 & 0 & 0 \\
\hline & 5 to $<6$ & 0 & 0 & 0 \\
\hline & 6 to $<7$ & 2 & 0 & 2 \\
\hline & 7 to 8 & 0 & 0 & 0 \\
\hline \multirow{4}{*}{$\begin{array}{l}\text { 7. Diversion and } \\
\text { transverse } \\
\text { colostomy }\end{array}$} & 4 to $<5$ & 0 & 0 & 0 \\
\hline & 5 to $<6$ & 0 & 1 & 1 \\
\hline & 6 to $<7$ & 0 & 1 & 1 \\
\hline & 7 to 8 & 0 & 0 & 0 \\
\hline \multirow{4}{*}{$\begin{array}{l}\text { 8. Empyema thoracis } \\
\text { decortication }\end{array}$} & 4 to $<5$ & 0 & 0 & 0 \\
\hline & 5 to $<6$ & 2 & 0 & 2 \\
\hline & 6 to $<7$ & 0 & 0 & 0 \\
\hline & 7 to 8 & 0 & 0 & 0 \\
\hline \multirow{4}{*}{ 9. Flap cover } & 4 to $<5$ & 0 & 0 & 0 \\
\hline & 5 to $<6$ & 0 & 0 & 0 \\
\hline & 6 to $<7$ & 0 & 1 & 1 \\
\hline & 7 to $<8$ & 0 & 0 & 0 \\
\hline \multirow{4}{*}{$\begin{array}{l}\text { 10. Pilomatrixoma } \\
\text { left thigh excision }\end{array}$} & 4 to $<5$ & 0 & 0 & 0 \\
\hline & 5 to $<6$ & 1 & 0 & 1 \\
\hline & 6 to $<7$ & 0 & 0 & 0 \\
\hline & 7 to 8 & 0 & 0 & 0 \\
\hline \multicolumn{5}{|c|}{$\begin{array}{l}\text { Table 2. Showing Numbers of Children with Success Smartphone } \\
\text { Distraction and Failed Smartphone Distraction }\end{array}$} \\
\hline
\end{tabular}

\section{DISCUSSION}

A significant number of children undergo surgery. A number of preoperative anxieties reducing intervention strategies, both pharmacological and non-pharmacological interventions, have been employed. Each intervention has its own benefits and limits. Anxiolytic premedication with midazolam has proven effective but it has got various disadvantages like delay in emergence, recovery and discharge, increased incidence of maladaptive behavioural changes post-surgery and amnesia. ${ }^{6}$ Concerning parental presence during induction of anaesthesia, the benefits of it would be less pre-operative sedation and less fear and anxiety during parent's separation. But the presence of parents during anaesthetic induction may change operating room routines, increase the number of people in the room and cause adverse reaction on parents and moreover, parents anxiety may worsen child's anxiety, prolong induction time and promote additional stress on the anaesthesiologist. ${ }^{9}$ Kain et al.10 compared the efficacy of programme allowing the presence of parents during anaesthetic induction with midazolam as preanesthetic medication and had observed that children belonging to the midazolam group had significantly less anxiety. Kain et al. ${ }^{3}$ in another study where children were submitted to a preparation program made up of information, visit to the operation room and role play oriented by specialist 1 to 10 days before surgery, preoperative and parental separation anxiety was found to be similar as compared to the non-participating group. The explanation might be that some sub-groups of children become more anxious after preparation such as children with previous experience, with emotional instability or aged 2 to 3 years. $^{3}$ Distraction techniques may be self-administered by the child (like playing with smartphone, videogame or toy) or may involve external personal (clowning and music therapy). Distraction with hand-held video game, video clips, cartoon distraction were found to be a very effective method to alleviate preoperative anxiety in children in certain studies. ${ }^{11,12,13}$

In our study, we are using smartphone as a distraction technique to alleviate pre-operative anxiety in children. Smartphone has many effects on children. Apart from causing distraction and disruption from study, smartphone also have many harmful effects. A study by Fredrik et al. ${ }^{14}$ indicated that cell phones affect the biology of brain. Those who used smartphones extensively experienced more sleep disturbance, restlessness and fatigue than those who were limited in using it. ${ }^{14}$ Despite of all these effects, we believe that our study will not harm the children as we are introducing smartphone for a total time of less than 2 hours.

Commonly preferred smartphone applications in our study were Talking Tom Cat $\AA$, Angry Bird $\AA$, Candy Crush $\AA$, Temple Run $2 \AA$ and animated Manipuri videos.

Almost all types of surgeries were done but most common surgery done in paediatric age groups in our hospital during the study period was herniotomy, accounting for $59 \%$ (Table 2). mYPAS was $\leq 30$ in operative for 91 children and in the rest 9 children mYPAS was $>30$ in operative room (Table 1). Number of children of the age group 4 - 5, 5 - 6, 6 - 7, 7 - 8 were $29,20,36,15$ respectively and number of failed distractions with smartphone i.e. mYPAS > 30 were $4,1,4,0$ respectively. The successful distraction rates were $86 \%$, $95 \%, 88 \%, 100 \%$ respectively. The mYPAS was highest among the age group of 4 - 5 years, a failed distraction rate of $14 \%$. We assume that children aged 4 - 5 years are vulnerable to anxiety due to their immature psychosocial development. The 9 children who experienced excessive anxiety with smartphone distraction were returned to pre-anaesthetic room for administration of midazolam $0.5 \mathrm{mg} / \mathrm{Kg}$ orally. However, the factors that increase anxiety need to be considered beforehand to prevent failure of the intervention.

Lastly, smartphones are readily available, easy to implement and portable. Moreover, smartphone are owned by many people even the parents hence the hospital doesn't have to provide additional devices and distraction with smartphone is pleasurable as it is familiar for most of the children and can be trained easily within half an hour even if it is unfamiliar. 


\section{CONCLUSIONS}

The use of smartphone which is readily available, easy to implement and portable, as a distraction technique is effective in reducing preoperative anxiety in children without using anxiolytic premedication.

Data sharing statement provided by the authors is available with the full text of this article at jemds.com.

Financial or other competing interests: None.

Disclosure forms provided by the authors are available with the full text of this article at jemds.com.

\section{REFERENCES}

[1] Wright KD, Stewart SH, Finley GA, et al. Prevention and intervention strategies to alleviate preoperative anxiety in children: a critical review. Behav Modif 2007;31(1):5279.

[2] Dreger VA, Tremback TF. Management of perioperative anxiety in children. AORN J 2006;84(5):778-804.

[3] Kain ZN, Mayes LC, Caramico LA. Preoperative preparation in children: a cross sectional study. J Clin Anaesth 1996;8(6):508-14.

[4] Kain ZN, MacLaren J, Mayes LC. Perioperative Behaviour stress in children. In: Cote CJ, Lerman J, ID Todres, eds. A Practice of Anesthesia for Infants and Children. Philadelphia, PA: Saunders Elsevier 2009:30-31.

[5] Kain ZN, Wang SM, Mayes LC, et al. Distress during the induction of anesthesia and postoperative behavioural outcomes. Anesth Analg 1999;88(5):1042-7.
[6] Watson AT, Visram A. Children's preoperative anxiety and postoperative behaviour. Paediatr Anaesth 2003;13:188204.

[7] LeRoy S, Elixson EM, O'Brien P, et al. Recommendations for preparing children and aldolescents for invasive cardiac procedures a statement from the American heart association pediatic nursing subcomittee of the council on cardiovascular nursing in collaboration with the council on cardiovascular diseases of the young. Circulation 2003;108(20):2550-64.

[8] Low DK, Pittaway AP. The iPhone induction-a novel use for the Apple iPhone. Paediatr Anesth 2008;18(6):573-4.

[9] McCann ME, Kain ZN. The management of preoperative anxiety in children: an update. Anesth Analg 2001;93(1):98-105.

[10] Kain ZN, Mayes LC, Wang SM, et al. Parental presence during induction of anaesthesia versus sedative premedication: which intervention is more effective? Anesthesiology 1998;89(5):1147-56.

[11] Patel A, Schieble T, Davidson M, et al. Distraction with a hand-held video game reduces pediatric preoperative anxiety. Paediatr Anaesth 2006;16(10):1019-27.

[12] Lee J, Lee J, Lim H, et al. Cartoon distraction alleviates anxiety in children during induction of anesthesia. Anesth Analg 2012;115(5):1168-73.

[13] Mifflin KA, Hackmann T, Chorney JM. Streamed video clips to reduce anxiety in children during inhaled induction of anesthesia. Anesth Analg 2012;115(5):1162-7.

[14] The Swedish Research Council. Wireless phone can affect the Brain, Swedish Study Suggests. Science Daily 2009. www.sciencedaily.com/2009/11/091111121251.htm. 